\title{
XLV. On the form of crystals of tin
}

\section{W.H. Miller M.A. F.R.S.}

To cite this article: W.H. Miller M.A. F.R.S. (1843) XLV. On the form of crystals of tin, Philosophical Magazine Series 3, 22:145, 263-265, DOI: $10.1080 / 14786444308636375$

To link to this article: http://dx.doi.org/10.1080/14786444308636375

$$
\text { 曲 Published online: } 01 \text { Jun } 2009 .
$$

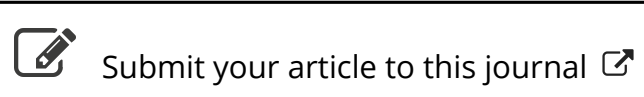

\footnotetext{
Џll Article views: 2
} 
perpendicular incidence, the reflected ray will be $l e f t$-handed, and vice versâ.

I have been prevented for some time from attending to the subject, but having now done so, and not observing that any of your other correspondents have taken up the subject, I beg to announce that $I$ have succeeded in verifying by experiment the above theoretical prediction.

My experiment was conducted by the use of Mr.Airy's "new analyser" described in the Cambridge Transactions, 1832, which does the same for right-and left-handed circular light, as the common analyser does for light polarized in opposite planes; that is, it stops one kind and transmits the other. This affords a ready test whether any given ray is right- or lefthanded. I procured the circular light by means of the Fresnel-rhomb, and on ascertaining that the light emerging from it was stopped by the Airy-analyser, I examined the same light after reflexion from glass at an incidence as near the perpendicular as possible, and found it transmitted by the analyser; thus proving its change from right- to left-handed.

I remain, Gentlemen, Your most obedient Servant,

Oxford, March 5, 1843.

B. Powerl.

XLV. On the Form of Crystals of Tin. By W. H. Miller, M.A., F.R.S., Professor of Mineralogy in the University of Cambridge*.

A LTHOUGH crystals of tin have been not unfrequently $A$ observed when the metal has been permitted to cool slowly after fusion, and also when it has been reduced by galvanic action, they appear to have been too imperfect to admit of the determination of their forms by measurement with the reflective goniometer. If however a feeble galvanic current, produced by one of Daniell's constant cells weakly charged, be transmitted through a solution of tin in hydrochloric acid, kept nearly saturated by suspending in the solution a piece of metallic tin connected with the copper element of the cell, in the course of four or five days very perfect crystals may be obtained.

These crystals belong to the pyramidal system.

The symbols of the different simple forms which have been observed, in the notation adopted in my treatise on Crystallography, will be as follows:-the letterdenoting one of the faces of each form being prefixed to the symbol of the form,

$a\{100\}, m\{110\}, p\{111\}, s\{101\}, r\{301\}, t\{331\}$.

* Communicated by the Author. 
It appears from a mean of the best of upwards of five hundred observed angles, that

$$
\frac{1}{a}=\frac{0.3857}{c}
$$

and that the angles between normals to the different faces are

\begin{tabular}{|c|c|c|c|}
\hline$a m$ & $45^{\circ} 0^{\prime}$ & $m t$ & $57^{\circ} 39^{\prime} \cdot 3$ \\
\hline$m a_{1}$ & 450 & $a s$ & $6854 \cdot 5$ \\
\hline$p p^{\prime}$ & $57 \quad 13$ & $a t$ & $40 \quad 50$ \\
\hline$s s^{\prime}$ & 4211 & $m p$ & 6123.5 \\
\hline$t t^{\prime}$ & 9820 & $m r$ & 3126 \\
\hline$r r$ & 1178 & $p p_{\imath}$ & 3935 \\
\hline$a p$ & $70 \quad 12.5$ & $r r_{1}$ & $74: 13 \cdot 2$ \\
\hline$a r$ & $5253 \cdot 4$ & $s s_{l}$ & 2929 \\
\hline$m s$ & $75 \quad 15.5$ & $t t_{i}$ & $64: 41 \cdot 3$ \\
\hline
\end{tabular}

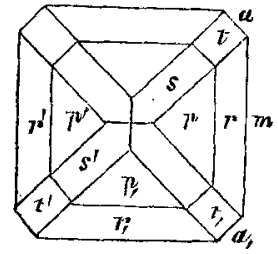

Twin crystals occur very frequently, the twin axis being either perpendicular to $p$ or to $r$.

In the crystals having the twin axis perpendicular to $p$, the angles between normals to the faces are

$$
\begin{array}{lrrrr}
\underline{p}^{\prime} p^{\prime} & 65^{\circ} 34^{\prime} & \underline{m m} & 57^{\circ} 13^{\prime} \\
\underline{r} & 120 & 5 & \underline{r}^{\prime \prime} r^{\prime \prime} & -539
\end{array}
$$

In the crystals having the twin axis per-

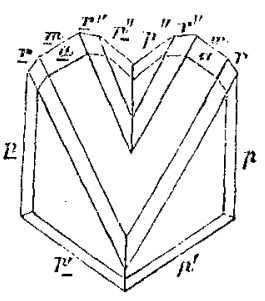
pendicular to the face $r$, the angles between normals to the faces are

$$
\begin{array}{lrrrrr}
\underline{p} p^{\prime} & 5^{\circ} 39^{\prime} & \underline{m} m & 1178^{\prime} \\
\underline{p p} & 120 & 5 & \underline{r^{\prime \prime} r^{\prime \prime}} & 54 & 16
\end{array}
$$

Some very slender capillary crystals of tin, said to have been obtained by fusion for which I am indebted to Mr. Brooke,

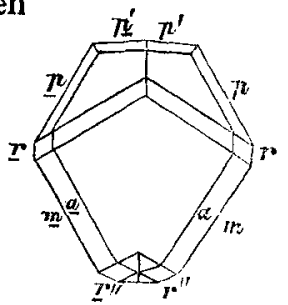
are regular eight-sided prisms, apparently a combination of the forms to which the faces $a, m$ belong. The crystalline markings seen on the surface of tin after cooling down from a state of fusion very closely resemble the confused crystallization which is occasionally produced when the metal is reduced by the galvanic current. Hence in all probability the crystals obtained by fusion have the same form as those produced by galvanic action.

At $10^{\circ} .5 \mathrm{C}$. the specific gravity of the crystals divided by that of water is $7 \cdot 178$. At the same temperature the specific gravity of a mass obtained by fusing the crystals divided by that of water was found to be $7 \cdot 293$. 
In conclusion I may observe, that tin is the only simple substance yet known, the crystals of which belong to the pyramidal system, and the only crystallizable metal not belonging either to the octahedral or rhombohedral system. It is also I believe the first instance in which the action of voltaic electricity has led to an accurate knowledge of a new crystalline species.

Cambridge, Feb. 3, 1843.

W. H. MrLler.

P.S. Since the above was sent for insertion in the Philosophical Magazine, I met with the following passage in a memoir by Professor Frankenheim, entitled "System der Krystalle," forming part of vol. xix. of the Nova Acta Acad. Nat. Cur. "According to Breithaupt, tin occurs in hexagonal prisms in the tin furnaces of Cornwall. By reduction at a low temperature I have always obtained it in tesseral forms." The hexagonal prisms of Breithaupt are in all pro-

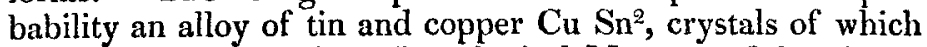
from a specimen in the Mineralogical Museum of Strasburg, were described by me in the Philosophical Magazine for February 1835. It does not appear whether Frankenheim observed any forms of the octahedral system excepting three faces at right angles to each other. The occurrence however of three faces at right angles to each other, though not an absolute proof that the crystals belong to the octahedral and not to the pyramidal system, would afford a strong presumption that they did in the present instance, inasmuch as $I$ have never been able to detect the slightest indication of a face perpendicular to the axis of the pyramid.

Cambridge, March 8, 1843.

W. H. M.

XLVI. On Sir G. C. Haughton's Experiments in Electricity related in the last Number. By J. P. Joule, Esq.

To the Editors of the Philosophical Magazine and Journal. Gentuemen,

A LLOW me to occupy a small portion of your space with $A$ a few observations on the subject of an interesting communication by Sir G.C. Haughton, inserted in your last Number.

On repeating the experiments on the action of frictional electricity upon the galvanometer, I find that the phænomenon to which Sir Graves has called attention is simply an example of the repulsion of bodies which are in the same electrical state, and is not sensibly owing to the minute currents which 